\title{
Increased HIV Prevention Program Coverage and Decline in HIV Prevalence Among Female Sex Workers in South India
}

\author{
Michel Alary, MD, PhD, * $+\neq$ Pradeep Banandur, MD, MPH, $\$$ \\ Subramanian Potty Rajaram, PhD, $\neq$ I Usha K. Thamattoor, MSc, $\neq / /$ Mandar K. Mainkar, PhD, ** \\ Ramesh Paranjape, PhD, ** Rajatashurva Adhikary, PhD, $+\dagger$ Thierry Duchesne, PhD, **+
}

Shajy Isac, PhD, I and Stephen Moses, MD, MPH $\$$ $\$ \oint$

\begin{abstract}
Background: As one way of assessing the impact of Avahan, the India AIDS Initiative of the Bill \& Melinda Gates Foundation, we examined the association between HIV prevention program indicators and changes in HIV prevalence among female sex workers (FSWs) between 2005 and 2009.

Methods: We conducted a secondary data analysis from 2 large crosssectional surveys (2005-2006 and 2008-2009) across 24 districts in south India ( $\mathrm{n}=11,000$ per round). A random-effect multilevel logistic regression analysis was performed using HIV as the outcome, with individual independent variables (from both surveys) at level 1 and district-level FSW-specific program indicators and contextual variables at level 2. Program indicators included their 2006 value, the difference in their values between 2008 and 2006, and the interaction between this difference and study round. Results: HIV prevalence among FSWs decreased from $17.0 \%$ to $14.2 \%(P$ $<0.001)$. This decline varied significantly $(P=0.006)$ across levels of difference in program coverage ( $\%$ of FSWs contacted by the program in a given year). Odds ratios comparing HIV prevalence between rounds changed with the level of increase in coverage and were statistically significant with
\end{abstract}

From the *Centre de recherche du CHU de Québec, Québec, Canada; $\dagger$ Département de médecine sociale et préventive, Université Laval, Québec, Canada; \$CHARME-India II Project, Bangalore, India; \$Department of Epidemiology, National Institute of Mental Health and Neurosciences, Bangalore, India; $\boldsymbol{\uparrow}$ Karnataka Health Promotion Trust, Bangalore, India; ||St John's Research Institute, Bangalore, India; **National AIDS Research Institute, Pune, India; $\dagger$ FHI 360, Washington, DC; ††Département de mathématiques et statistique, Université Laval, Québec, Canada; and $\S \S$ Department of Community Health Sciences, University of Manitoba, Winnipeg, Canada

Acknowledgments: The authors thank all the field data collection teams and the women who agreed to participate in the surveys. Without them, this study would not have been possible. We also thank Tinku Thomas for her contribution to the data analysis. This research was funded by the Bill \& Melinda Gates Foundation. The views expressed herein are those of the authors and do not necessarily reflect the official policy or position of the Bill \& Melinda Gates Foundation. There is no conflict of interest.

This study was presented, in part, at the STI \& AIDS World Congress; Vienna; July 14-17, 2013.

Correspondence: Michel Alary, MD, PhD, CHU de Québec, Hôpital du Saint-Sacrement, 1050 Chemin Ste-Foy, Québec, QC, Canada G1S 4L8. E-mail: malary@uresp.ulaval.ca.

Received for publication January 22, 2014, and accepted April 9, 2014.

Supplemental digital content is available for this article. Direct URL citations appear in the printed text, and links to the digital files are provided in the HTML text of this article on the journal's Web site (http://www.stdjournal.com).

This is an open-access article distributed under the terms of the Creative Commons Attribution-NonCommercial-NoDerivatives 3.0 License, where it is permissible to download and share the work provided it is properly cited. The work cannot be changed in any way or used commercially.

DOI: 10.1097/OLQ.0000000000000138

Copyright (C) 2014 American Sexually Transmitted Diseases Association All rights reserved. coverage increase $\geq$ quartile (Q) 1: odds ratio, 0.85 at Q1; 0.78 at Q2; 0.66 at Q3; and 0.51 at $\mathrm{Q} 4$.

Conclusions: These findings suggest that increased program coverage was associated with declining HIV prevalence among FSWs covered by the Avahan program. The triangulation of our results with those from other approaches used in evaluating Avahan suggests a major impact of this intervention on the HIV epidemic in southern India.

$A$ vahan, the India AIDS Initiative of the Bill \& Melinda Gates Foundation, is a comprehensive HIV prevention program targeting the most at-risk populations in the states of India most affected by the HIV epidemic (Andhra Pradesh, Karnataka, Maharashtra, and Tamil Nadu in the south of the country, and Manipur and Nagaland in the northeast). It was initially implemented through a network of nongovernmental organizations (NGOs) and has progressively been transferred to government agencies and community-based organizations since 2008 .

Because cluster randomized designs have major limitations for evaluating complex large-scale interventions, ${ }^{1,2}$ the initial impact evaluation plan for Avahan included serial cross-sectional studies in the high-risk populations, based on which sophisticated mathematical models were developed to estimate program impact in those populations, and in the general population. ${ }^{1,3}$ The use of this modeling approach has been complicated by the lack of adequate baseline data, ${ }^{4}$ but recently, published results using this approach suggest a major impact of Avahan on the HIV epidemic in Karnataka ${ }^{5,6}$ and in the 4 South India states mentioned above. ${ }^{7}$ A purely statistical approach based on HIV surveillance data among pregnant women was also used to estimate the overall Avahan impact in the 6 Avahan states. ${ }^{8}$ Although suggesting a positive impact of the intervention in the general population, this study has the limitation of not taking into account the nature of the Avahan intervention, including its various components, and does not allow for the analysis of the actual mechanism leading to the impact. ${ }^{9}$

We examined changes over time occurring in HIV prevalence among female sex workers (FSWs), the largest risk population in the program, between 2 large surveys carried out in 2005 to 2006 and 2008 to 2009 , in 24 districts of the 4 southern states of India covered by Avahan, where the HIV epidemic is predominantly heterosexual and mainly driven by sex work. ${ }^{10,11}$ As indicators related to program coverage and implementation have shown very sharp increases between baseline and 2008, ${ }^{12}$ we considered the impact of these increases on the changes in HIV prevalence between surveys. Given the heterogeneity of the HIV epidemic in India, ${ }^{13}$ it is important to also consider the influence of broader contextual factors that may have an impact on the HIV epidemic in high-risk groups. We therefore carried out a multilevel statistical analysis of the individual, contextual and program factors impacting on HIV prevalence among FSWs, and on the changes in the prevalence levels between the 2 survey rounds. 


\section{METHODS}

\section{Data Sources}

The design and study procedures of the cross-sectional studies, known as integrated behavioral and biological assessments (IBBAs), have been described in detail elsewhere ${ }^{14,15}$ and are summarized in the Supplementary Online Material Methods section, http://inks.lww.com/OLQ/A86, as are the main components of the Avahan intervention.

The common set of program indicators for all districts covered by Avahan has been described extensively elsewhere. ${ }^{12}$ For the purpose of the present analysis, we used data collected by the NGOs implementing the intervention in each district along with complementary information to estimate: (1) program coverage (proportion of FSWs contacted by the program at least once in a given year), (2) the proportion of FSWs contacted monthly, and (3) the proportion of condom requirement met in a given year (number of condoms distributed in a given year divided by the estimated number of commercial sexual acts by all FSWs in the same year). Details on the methods used to derive these estimates are provided in the Supplementary Online Material Methods section, http://links.lww.com/OLQ/A86. The 3 indicators were computed for years 2006 to 2008 because the information was complete for all districts only for that period (the program started being handed over to the government in 2008). In the statistical models, we used the 2006 values of the indicators and the difference between the 2008 and 2006 values.

We considered a total of 53 district-level contextual variables for inclusion in the multilevel statistical model (see complete list in the Supplementary Online Material Table, http://links.lww.com/OLQ/A87).

The study and its consent procedures were approved by the ethics committees of all institutions that were involved in the data collection for this study (see Supplementary Online Material Methods section for more details on ethical considerations http://links.lww.com/OLQ/A86).

\section{Statistical Analyses}

We assessed differences in personal characteristics between participants who were tested for HIV and those who were not, and between participants in round 1 and those in round 2 , using the $\chi^{2}$ test. We compared HIV prevalence between the study rounds for each of the 24 IBBA districts. We then built multilevel (FSW personal characteristics at level 1 and districtlevel contextual and program variables at level 2) logistic regression models with HIV prevalence as the outcome, using the round 1 and round 2 merged data set. Study round was considered as the main independent variable in our analyses because the difference in HIV prevalence between the rounds was our central interest. We also preselected a certain number of the individual variables from the questionnaire for inclusion as independent variables in the model because they could be confounders of the differences observed between rounds. This was done based on variables previously identified to be associated with HIV in the first IBBA round ${ }^{14}$ and of a priori knowledge from the literature (see the Supplementary Online Table for the complete list of individual variables considered). We entered all of these variables into a multilevel logistic regression model with a random intercept for the districts and a random coefficient for round because the difference in HIV prevalence varied widely between districts. We then removed sequentially from this model all the individual variables with $P>0.05$, as long as they were not confounding the other associations, to arrive at a model with individual variables only.

We preselected the contextual variables for addition to the models above based on linear regression models with the aggregate HIV prevalence rate in each district as the dependent variable and the contextual variables as the independent variables. Those with a $P$ value less than 0.05 in these models were then added to the previous multilevel models. Baseline HIV prevalence among FSWs in each district was also included in the model as an additional district-specific variable. The removal of nonsignificant variables at this stage led to the basic model with individual and district-level contextual variables.

To the basic model, we then added the 3 pairs of districtlevel program variables (2006 value and difference between 2008 and 2006), along with the interaction terms between the 2008 to 2006 difference and the round. We kept in the model only the program variables corresponding to a significant interaction $(P<0.05)$ with the round. Finally, because we were interested in factors that could impact the differences in the outcomes observed between the IBBA rounds, we examined oneby-one the interaction terms between the round and each of the other individual and district-level contextual factors included in the first multilevel model described above. We kept the statistical interactions that reached $P<0.05$ in these models. This led to the final model, with assessment of the intervention impact, through the interaction terms between the study round and the 2008 to 2006 differences in program variables, and inclusion of other factors having a multiplicative statistical interaction with the round. All analyses described above were carried out using STATA IC 11.1 for Windows (StataCorp LP, College Station, TX).

\section{RESULTS}

Among the 14,601 women approached in round 1, 11,690 $(80.1 \%)$ answered the questionnaire. Among the latter, 10,806 were tested for HIV $(92.4 \%), 10,716(91.7 \%)$ for syphilis, and $10,674(91.3 \%)$ for gonorrhea and chlamydia (NG/CT). The overall participation rate was slightly lower in 2008: 15,682 women were approached, of whom 11,486 (73.2\%) answered the questionnaire; however, among the participants, 10,901 (95.0\%) were tested for HIV, 10,806 (94.1\%) for syphilis and 10,880 (94.8\%) for NG/CT. No data were available to compare participants with nonparticipants. However, Table 1 shows the comparison between participants who were tested for HIV and those who were interviewed only. There were significant differences for most variables examined. This is, however, largely due to the very large sample sizes of these surveys. In addition, the proportions among all participants were almost identical to those among those tested for HIV (see the "Total" columns in Table 1).

Table 2 shows the comparison between various characteristics of participating FSWs between rounds 1 and 2 . The differences were significant for most variables examined. However, this was mostly for behavior or infections that were targeted by the Avahan program, such as condom use, violence, NG/CT, and syphilis prevalence. For the other significant variables, the actual differences in the distribution of their values between rounds were mostly small, with the statistical significance often due to the very large sample sizes of these surveys.

HIV prevalence declined significantly from $17.0 \%$ to $14.2 \%(P<0.001)$ from $2005-2006$ to 2008-2009 (Table 3). This decline was significant in 2 of the 4 states and 10 of the 24 districts. There was an increase in HIV prevalence in 4 districts, but it was statistically significant in only 1 . Table 3 also shows the variation in program coverage and condom requirement met between the study rounds. There was a significant correlation between changes in HIV prevalence between 2006 and 2008 and changes in coverage (Spearman $r=-0.410, P=0.048$ ), whereas such an association was borderline significant when considering condom requirement met (Spearman $r=-0.398, P=0.054$ ). 
TABLE 1. Comparison of the Characteristics of Female Sex Workers Providing and Not Providing a Biological Sample Among Those Interviewed in Survey Rounds 1 and 2

\begin{tabular}{|c|c|c|c|c|c|c|c|c|}
\hline \multirow[b]{2}{*}{ Variable } & \multicolumn{4}{|c|}{ Round 1} & \multicolumn{4}{|c|}{ Round 2} \\
\hline & $\begin{array}{c}\text { Interview } \\
\text { Only }(\mathbf{n}=\mathbf{8 8 4}) \\
\%\end{array}$ & $\begin{array}{c}\text { Interview and } \\
\text { Biological Sample } \\
(\mathrm{n}=\mathbf{1 0 , 8 0 6}) \\
\%\end{array}$ & $\begin{array}{c}\text { Total } \\
(n=\underset{11,690)}{\%},\end{array}$ & $P^{*}$ & $\begin{array}{c}\text { Interview } \\
\text { Only }(\mathbf{n}=\mathbf{5 8 5}), \\
\%\end{array}$ & $\begin{array}{c}\text { Interview and } \\
\text { Biological Sample } \\
(\mathbf{n}=\mathbf{1 0 , 9 0 1 )} \\
\%\end{array}$ & $\begin{array}{c}\text { Total } \\
(\mathrm{n}=\mathbf{1 1 , 4 8 6 )}, \\
\%\end{array}$ & $P^{*}$ \\
\hline \multicolumn{9}{|l|}{ Current age, y } \\
\hline $15-24$ & 24.7 & 20.9 & 21.2 & \multirow[t]{3}{*}{$<0.001$} & 22.6 & 17.8 & 18.0 & \multirow[t]{3}{*}{$<0.001$} \\
\hline $25-34$ & 52.0 & 45.9 & 46.3 & & 47.5 & 44.3 & 44.4 & \\
\hline $35+$ & 23.3 & 33.3 & 32.5 & & 29.9 & 38.0 & 37.6 & \\
\hline \multicolumn{9}{|l|}{ Literacy } \\
\hline Illiterate & 70.8 & 65.1 & 65.6 & \multirow[t]{2}{*}{0.001} & 52.1 & 60.7 & 60.2 & \multirow[t]{2}{*}{$<0.001$} \\
\hline Literate & 29.2 & 34.9 & 34.4 & & 47.9 & 39.3 & 39.8 & \\
\hline \multicolumn{9}{|c|}{ Source of income other than sex work } \\
\hline No & 76.2 & 57.1 & 58.5 & \multirow[t]{2}{*}{$<0.001$} & 62.0 & 54.1 & 54.5 & \multirow[t]{2}{*}{$<0.001$} \\
\hline Yes & 23.8 & 42.9 & 41.5 & & 38.0 & 45.9 & 45.5 & \\
\hline \multicolumn{9}{|c|}{ Current marital status } \\
\hline $\begin{array}{l}\text { Currently } \\
\text { married }\end{array}$ & 57.7 & 59.3 & 59.2 & \multirow[t]{3}{*}{$<0.001$} & 56.2 & 63.4 & 63.0 & \multirow[t]{3}{*}{$<0.001$} \\
\hline $\begin{array}{l}\text { Marriage } \\
\text { dissolved }\end{array}$ & 18.1 & 28.7 & 27.9 & & 23.4 & 26.4 & 26.3 & \\
\hline Never married & 24.2 & 12.0 & 12.9 & & 20.3 & 10.2 & 10.7 & \\
\hline \multicolumn{9}{|l|}{ Age at sex debut, y } \\
\hline$<15$ & 21.3 & 27.0 & 26.6 & \multirow[t]{2}{*}{$<0.001$} & 25.2 & 28.0 & 27.8 & \multirow[t]{2}{*}{0.147} \\
\hline $15+$ & 78.7 & 73.0 & 73.4 & & 74.8 & 72.0 & 72.2 & \\
\hline \multicolumn{9}{|c|}{ Duration in sex work, $y$} \\
\hline$<2$ & 15.3 & 17.3 & 17.2 & \multirow[t]{4}{*}{0.197} & 17.4 & 16.5 & 16.5 & \multirow[t]{4}{*}{0.011} \\
\hline $2-4$ & 31.9 & 33.3 & 33.2 & & 38.7 & 34.7 & 34.9 & \\
\hline $5-9$ & 29.1 & 26.5 & 26.7 & & 27.7 & 26.8 & 26.9 & \\
\hline $10+$ & 23.7 & 22.8 & 22.9 & & 16.3 & 22.0 & 21.7 & \\
\hline \multicolumn{9}{|l|}{ Place of solicitation } \\
\hline Home & 12.4 & 21.5 & 20.8 & \multirow[t]{4}{*}{$<0.001$} & 8.7 & 15.4 & 15.1 & \multirow[t]{4}{*}{$<0.001$} \\
\hline $\begin{array}{l}\text { Brothel/Lodge/ } \\
\text { Dhaba }\end{array}$ & 43.6 & 21.7 & 23.3 & & 29.3 & 19.6 & 20.1 & \\
\hline Public places & 43.2 & 53.8 & 53.0 & & 54.6 & 58.1 & 57.9 & \\
\hline Other & 0.8 & 3.0 & 2.9 & & 7.4 & 6.9 & 6.9 & \\
\hline Experienced violen & & & & & & & & \\
\hline No & 90.7 & 87.8 & 88.0 & 0.009 & 89.6 & 92.0 & 91.9 & 0.039 \\
\hline Yes & 9.3 & 12.2 & 12.0 & & 10.4 & 8.0 & 8.1 & \\
\hline Has a nonpaying $\mathrm{m}$ & in partner & & & & & & & \\
\hline No & 51.0 & 36.8 & 37.9 & $<0.001$ & 46.0 & 37.5 & 37.9 & $<0.001$ \\
\hline Yes & 49.0 & 63.2 & 62.1 & & 54.0 & 62.5 & 62.1 & \\
\hline Consistent condom & Ise with clients & & & & & & & \\
\hline No & 21.4 & 35.9 & 34.8 & $<0.001$ & 15.9 & 16.0 & 16.0 & 0.952 \\
\hline Yes & 78.6 & 64.1 & 65.2 & & 84.1 & 84.0 & 84.0 & \\
\hline Client volume & & & & & & & & \\
\hline$<10$ per week & 53.7 & 63.2 & 62.8 & $<0.001$ & 52.3 & 59.6 & 59.2 & $<0.001$ \\
\hline $10+$ per week & 46.3 & 36.8 & 37.2 & & 47.7 & 40.4 & 40.8 & \\
\hline
\end{tabular}

$* P$ value for the $\chi^{2}$ test comparing the distribution of characteristics of participants providing and those not providing a biological sample, with appropriate degrees of freedom

The 2 latter program indicators were also highly correlated together (Spearman $r=0.647, P=0.006$ ). The difference in the proportion of FSWs contacted on a monthly basis between 2006 and 2008 was not significantly correlated with the changes in HIV prevalence (Spearman correlation coefficient $=-0.1992$, $P=0.351)$ or with the changes in the other program indicators (data not shown).

The left columns of Table 4 show the results of the multilevel model without program variables and interaction terms. The adjusted odds ratio (AOR) comparing HIV prevalence in round 2 with that in round 1 was 0.76 , with a narrow $95 \%$ confidence interval $(95 \% \mathrm{CI})$ of 0.67 to 0.85 . A number of demographic and behavioral variables were associated with HIV (Table 4). Surprisingly, women reporting consistent condom use with clients and carrying condoms with them had a significantly higher HIV prevalence. The only significant contextual variable among those examined was mean age at marriage of girls, with an approximately $8 \%$ lower HIV prevalence for each year of increase in this district-level variable. As expected, baseline HIV prevalence was also strongly associated with overall HIV prevalence. The random coefficient for the round had a variance significantly higher than zero, reflecting the high level of heterogeneity in the changes in HIV prevalence across districts. The variance of the random intercept, although much lower than in the null model, was also significantly different from zero (Table 4).

The right columns of Table 4 show that there was a significant negative interaction between the round and changes in program coverage between 2006 and 2008. The interaction terms 
TABLE 2. Comparison of Selected Individual Characteristics of Female Sex Workers Between Survey Rounds 1 and 2

\begin{tabular}{|c|c|c|c|}
\hline Characteristics & $\begin{array}{c}\text { Round 1 } \\
(\mathrm{n}=\mathbf{1 0 , 8 0 6})\end{array}$ & $\begin{array}{c}\text { Round 2 } \\
(\mathrm{n}=\mathbf{1 0 , 9 0 1 )}\end{array}$ & $P^{*}$ \\
\hline Current age, $\mathrm{y}$ & & & $<0.001$ \\
\hline $15-24$ & 20.8 & 17.8 & \\
\hline $25-34$ & 45.8 & 44.3 & \\
\hline $35+$ & 33.3 & 38.0 & \\
\hline Literacy & & & $<0.001$ \\
\hline Illiterate & 65.2 & 60.6 & \\
\hline Literate & 34.8 & 39.4 & \\
\hline $\begin{array}{l}\text { Source of income other than } \\
\text { sex work }\end{array}$ & & & $<0.001$ \\
\hline No & 57.1 & 54.1 & \\
\hline Yes & 42.9 & 45.9 & \\
\hline Current marital status & & & $<0.001$ \\
\hline Currently married & 59.2 & 63.4 & \\
\hline Marriage dissolved & 28.7 & 26.4 & \\
\hline Never married & 12.1 & 10.2 & \\
\hline Age at sexual debut, y & & & 0.150 \\
\hline$<15$ & 27.1 & 28.0 & \\
\hline $15+$ & 72.9 & 72.0 & \\
\hline Duration in sex work, $\mathrm{y}$ & & & 0.063 \\
\hline$<2$ & 17.3 & 16.5 & \\
\hline $2-4$ & 33.3 & 34.7 & \\
\hline $5-9$ & 26.5 & 26.8 & \\
\hline $10+$ & 22.9 & 22.0 & \\
\hline Place of solicitation & & & $<0.001$ \\
\hline Home & 21.5 & 15.5 & \\
\hline Brothel/Lodge/Dhaba & 21.7 & 19.6 & \\
\hline Public places & 53.7 & 58.1 & \\
\hline Other & 3.0 & 6.9 & \\
\hline Carrying condoms & & & $<0.001$ \\
\hline No & 56.0 & 40.1 & \\
\hline Yes & 44.0 & 59.9 & \\
\hline $\mathrm{NG} / \mathrm{CT}^{\dagger}$ & & & $<0.001$ \\
\hline No & 92.8 & 94.1 & \\
\hline Yes & 7.2 & 5.9 & \\
\hline Experienced violence & & & $<0.001$ \\
\hline No & 87.8 & 92.0 & \\
\hline Yes & 12.2 & 8.0 & \\
\hline Has a nonpaying main partner & & & 0.330 \\
\hline No & 63.1 & 62.5 & \\
\hline Yes & 36.9 & 37.5 & \\
\hline Syphilis serological test result & & & $<0.001$ \\
\hline Negative & 88.3 & 92.9 & \\
\hline Positive & 11.7 & 7.1 & \\
\hline $\begin{array}{l}\text { Consistent condom use with } \\
\text { clients }\end{array}$ & & & $<0.001$ \\
\hline No & 35.8 & 16.0 & \\
\hline Yes & 64.2 & 84.0 & \\
\hline
\end{tabular}

* $P$ value for the $\chi^{2}$ test comparing the distribution of characteristics of participants between the study rounds.

${ }^{\dagger}$ Infection by either Neisseria gonorrhoeae or Chlamydia trachomatis.

between the round and changes in other program variables were not statistically significant and thus not kept in the model. Both baseline HIV prevalence and having a regular nonpaying partner also had significant multiplicative interactions with survey round. The only variable not involved in the interaction terms that did not remain significant compared with the previous model was mean age at marriage of girls at the district level. The variance of the random coefficient for the round, though significantly different from zero, was lower than that in the previous model, whereas the variance of the random intercept was now close to null in this model (Table 4).

Table 5 shows the decreases in HIV prevalence for the various categories of variables shown to have an interaction with the study round from the results presented in Table 4 . The decrease in HIV prevalence was not as strong among women with a main nonpaying partner compared with those without, although the latter had a higher overall HIV prevalence. The decrease in HIV prevalence was not significant in districts with very low baseline HIV prevalence and significant for higher values starting at about the first quartile of this variable. Finally, there was a stronger decline in HIV prevalence in districts with a larger increase in program coverage between 2006 and 2008 (Table 5). The decrease in HIV prevalence was not significant when coverage was higher in 2006 than in 2008.

\section{DISCUSSION}

This multilevel analysis shows significant declines in HIV prevalence among FSWs in southern India between 2005 and 2009 that are strongly associated with increases in Avahan program coverage, thus suggesting a positive impact of the FSW intervention component of this intervention where implemented in a way ensuring sufficient increase in program coverage up until 2008. Indeed, larger increases in program coverage at the district level led to larger declines in HIV prevalence, with no significant decrease in districts occurring without an increase in coverage, and a reduction of approximately $50 \%$ in HIV prevalence in the districts with the highest increases in coverage.

This analysis controlled for a number of individual and contextual factors that could have potentially confounded this association, as well as for baseline HIV prevalence at the district level and its interaction with the round, thus taking into account the fact that decreases in prevalence were more likely to occur in districts with higher baseline values. The use of a random coefficient for the round took into account the wide variability in the changes in HIV prevalence between districts.

It was difficult to fully address the impact of the program indicator on condom requirement met because of the high correlation between its 2006 to 2008 district-level variation and that of program coverage. However, the borderline significant correlation between increases in condom requirement met and decreases in HIV prevalence at the district-level suggests that this indicator is also part of the mechanism leading to impact. Finally, it is possible that the actual coverage of the program is more important in terms of impact than the frequency of the contacts with the target population, as long as some (unknown) threshold is reached for the latter.

The associations that we found between HIV prevalence and the individual variables considered in the analysis are largely similar to what was found in an analysis of round 1 data. ${ }^{14}$ That condom use and condom carriage were both associated with a higher HIV prevalence may be due to reverse causation, with FSWs having acquired HIV before being reached by the interventions and starting to use condoms once they learned more about HIV, especially when they discovered their serological status. A similar phenomenon was observed in studies of the general population in southern India. ${ }^{13,16}$ Among the contextual district-level variables considered, only mean age at marriage of girls was significantly associated with HIV in the basic model. Interestingly, this factor was also associated with HIV prevalence among pregnant women attending antenatal care clinics in the same IBBA districts. ${ }^{17}$ However, in the model with program variables, mean age at marriage was not a significant predictor of HIV. Careful examination of the data showed that it was the introduction of the interaction between baseline HIV prevalence and the round that was mainly confounding this association (data not shown).

The results of this study constitute a significant addition to the overall picture of the Avahan impact evaluation. Whereas 
TABLE 3. Comparison of HIV Prevalence (in percent), Program Coverage* and Condom Requirement Met ${ }^{\dagger}$ Between 2 Cross-Sectional Surveys Carried Out in 2005 to 2006 (Round 1) and 2008 to 2009 (Round 2) Among FSWs in 24 Districts of Four Southern States of India

\begin{tabular}{|c|c|c|c|c|c|c|c|c|c|c|}
\hline \multirow[b]{2}{*}{ State/District } & \multicolumn{4}{|c|}{ HIV Prevalence } & \multicolumn{3}{|c|}{ Program Coverage } & \multicolumn{3}{|c|}{ Condom Requirement Met } \\
\hline & $\begin{array}{c}\text { Round } \\
1\end{array}$ & $\begin{array}{c}\text { Round } \\
2\end{array}$ & $\boldsymbol{P}$ & $\begin{array}{l}\text { Round } 2 \text { Minus } \\
\text { Round } 1\end{array}$ & $\begin{array}{c}\text { Round } \\
1\end{array}$ & $\begin{array}{c}\text { Round } \\
2\end{array}$ & $\begin{array}{l}\text { Round } 2 \text { Minus } \\
\text { Round } 1\end{array}$ & $\begin{array}{c}\text { Round } \\
1\end{array}$ & $\begin{array}{c}\text { Round } \\
2\end{array}$ & $\begin{array}{l}\text { Round } 2 \text { Minus } \\
\text { Round } 1\end{array}$ \\
\hline Andhra Pradesh & 16.3 & 11.3 & $<0.001$ & -5.0 & 28.1 & 81.3 & +53.2 & 19.7 & 97.4 & +77.7 \\
\hline Chitoor & 8.7 & 12.1 & 0.123 & +3.4 & 29.8 & 96.1 & +66.3 & 1.3 & 66.5 & +65.2 \\
\hline East Godavari & 24.4 & 21.7 & 0.356 & -2.7 & 21.5 & 52.1 & +30.6 & 27.1 & 131.6 & +104.5 \\
\hline Guntur & 20.5 & 13.8 & 0.012 & -6.7 & 31.9 & 67.5 & +35.6 & 17.8 & 132.3 & +114.5 \\
\hline Hyderabad & 14.8 & 13.7 & 0.665 & -1.1 & 26.2 & 90.9 & +64.7 & 4.0 & 46.6 & +42.6 \\
\hline Karimnagar & 22.8 & 7.0 & $<0.001$ & -15.8 & 30.8 & 100.2 & +69.4 & 21.4 & 71.6 & +50.2 \\
\hline Prakasham & 10.2 & 8.8 & 0.519 & -1.4 & 26.6 & 83.2 & +56.6 & 49.2 & 133.7 & +84.5 \\
\hline Visakhapatnam & 14.8 & 9.8 & 0.027 & -5.0 & 26.4 & 51.3 & +24.9 & 41.0 & 136.6 & +95.6 \\
\hline Warangal & 13.9 & 3.7 & $<0.001$ & -10.2 & 20.2 & 91.0 & +70.8 & 10.2 & 41.0 & +30.8 \\
\hline Maharashtra & 22.5 & 22.2 & 0.793 & -0.3 & 80.8 & 80.1 & -0.7 & 20.2 & 43.8 & +23.6 \\
\hline Kolhapur & 33.0 & 27.4 & 0.292 & -5.6 & 45.3 & 114.1 & +68.8 & 28.6 & 103.0 & +74.4 \\
\hline Mumbai & 21.5 & 23.0 & 0.376 & 1.5 & 92.9 & 87.0 & -5.9 & 24.6 & 46.9 & +22.3 \\
\hline Parbhani & 15.3 & 14.9 & 0.883 & -0.4 & 63.2 & 84.8 & +21.6 & 50.6 & 80.0 & +29.4 \\
\hline Pune & 35.1 & 23.2 & $<0.001$ & -11.9 & 5.2 & 22.3 & +17.1 & 3.7 & 32.8 & +29.1 \\
\hline Thane & 12.2 & 20.7 & $<0.001$ & +8.5 & 106.0 & 97.1 & -8.9 & 16.4 & 29.6 & +13.2 \\
\hline Yevatmal & 37.3 & 26.8 & 0.047 & -10.5 & 26.8 & 53.2 & +26.4 & 40.2 & 160.0 & +119.8 \\
\hline Tamil Nadu & 8.1 & 7.2 & 0.285 & -0.9 & 78.5 & 94.2 & +15.7 & 88.8 & 71.7 & -17.1 \\
\hline Chennai & 3.2 & 2.0 & 0.303 & -1.2 & 86.5 & 106.3 & +19.8 & 67.8 & 89.9 & +22.1 \\
\hline Coimbatore & 6.1 & 6.8 & 0.705 & 0.7 & 84.8 & 93.7 & +8.9 & 99.3 & 67.2 & -32.1 \\
\hline Dharmapuri & 12.8 & 7.4 & 0.011 & -5.4 & 106.4 & 117.3 & +10.9 & 102.3 & 82.8 & -19.5 \\
\hline Madurai & 5.7 & 8.3 & 0.149 & 2.6 & 72.4 & 88.0 & +15.6 & 94.1 & 75.2 & -18.9 \\
\hline Salem & 12.7 & 11.3 & 0.544 & -1.4 & 61.7 & 79.6 & +17.9 & 86.0 & 47.7 & -38.3 \\
\hline Karnataka & 18.0 & 13.0 & $<0.001$ & -5.0 & 34.6 & 99.7 & +65.1 & 30.6 & 87.7 & +57.1 \\
\hline Bangalore & 11.3 & 7.7 & 0.022 & -3.6 & 19.4 & 125.6 & +106.2 & 35.2 & 102.7 & +67.5 \\
\hline Belgaum & 34.2 & 27.5 & 0.048 & -6.7 & 17.5 & 57.5 & +40.0 & 13.2 & 77.2 & +64.0 \\
\hline Bellary & 15.6 & 14.4 & 0.614 & -1.2 & 94.2 & 111.4 & +17.2 & 69.2 & 83.8 & +14.6 \\
\hline Shimoga & 10.5 & 9.4 & 0.586 & -1.1 & 77.5 & 120.1 & +42.6 & 23.0 & 80.7 & +57.7 \\
\hline Mysore & 24.2 & 11.1 & $<0.001$ & -13.1 & 64.7 & 97.4 & +32.7 & 16.1 & 53.8 & +37.7 \\
\hline Total & 17.0 & 14.2 & $<0.001$ & -2.8 & 55.1 & 87.6 & +32.5 & 34.4 & 73.6 & +39.2 \\
\hline
\end{tabular}

*Percentage of the FSW population contacted at least once by the program in the previous year. This was computed from the number of FSWs contacted at least once by the program in the previous year divided by the estimation of the size of the FSW population on the same year.

†Percentage of the condoms required by FSWs for all sex acts with clients in a given year. This was computed based on the number of condoms distributed to FSWs by the NGOs in a given year as the numerator, whereas the denominator was the expected number of condoms needed by FSWs in the district, based on the estimated number of FSWs in the district and the mean number of client-contacts estimated from the cross-sectional survey data.

it has been shown that the implementation of the program was highly successful, ${ }^{12}$ that favorable time trends in intermediate outcomes (e.g., condom use and prevalence of curable sexually transmitted infections) occurred after implementation, ${ }^{18-20}$ that condom use was positively associated ${ }^{21}$ and sexually transmitted infection prevalence negatively associated ${ }^{22}$ with exposure to the intervention, and that the program seemingly had an impact on HIV prevalence at the general population level, ${ }^{8,23}$ the evidence for an impact on HIV prevalence among FSWs has so far been limited to time trends observed ${ }^{19,20}$ and mathematical modeling studies ${ }^{5-7}$ based on these trends. This is the first study showing a direct relationship between program exposure assessed through routine program monitoring and decrease in HIV prevalence in one of the vulnerable populations targeted by the intervention.

However, there are a number of limitations to this study. First, there was no randomization of the intervention and the assessment of the impact relies only on serial observational data. The decision not to use a randomized design for this evaluation was taken right at the start for reasons that have been summarized in previous publications. ${ }^{1,3}$ The limitations of communityrandomized trials for "real-world" evaluations have since that time been acknowledged more widely. ${ }^{2}$ Furthermore, we were able to demonstrate an association between the level of intervention coverage and decreases in HIV prevalence at the district level, thus reaching a level of plausibility in the attribution of the impact on HIV prevalence to Avahan as per the framework proposed by Habicht et al. ${ }^{24}$

Second, we do not know the characteristics of the women who declined participation in the surveys and the proportion of refusals increased between the 2 rounds. It is impossible to assess the impact of refusals on the observed trends because no information is available on the women who did not participate. In addition, there were significant differences between women who provided biological samples and those who only accepted to be interviewed. However, for most variables, these differences were of small magnitude, given the very large sample sizes, or went in the same direction in both survey rounds. Moreover, the distribution of the variables considered in Table 1 among all participants was almost identical to that among those tested for HIV, because the proportion of FSWs not providing a sample among the participants was low in both rounds. Thus, important biases resulting from these differences when comparing HIV prevalence in both rounds are unlikely. Similar observations are relevant to the comparison of the characteristics of the participants between the rounds (Table 2): apart for the changes expected because of the intervention, the absolute differences were mostly small, although often statistically significant because of the very large sample sizes. 
TABLE 4. Results of the Multilevel Logistic Regression Models of Individual-, Programmatic-, and District-Level Determinants of HIV Prevalence Among FSWs in 24 Districts in South India, 2005 to 2009

\begin{tabular}{|c|c|c|c|c|c|}
\hline \multirow{2}{*}{$\begin{array}{l}\text { Characteristics } \\
\text { Fixed Part of the Model }\end{array}$} & \multicolumn{2}{|c|}{$\begin{array}{l}\text { Without Program Variables } \\
\text { and Interaction Terms }\end{array}$} & \multicolumn{3}{|c|}{$\begin{array}{c}\text { With Program Variables and } \\
\text { Interaction Terms }\end{array}$} \\
\hline & AOR $^{*}$ & $95 \% \mathrm{CI}^{*}$ & $\mathbf{A O R}^{\dagger}$ & $\boldsymbol{P}^{\dagger}$ & $95 \% \mathrm{CI}^{\dagger}$ \\
\hline Intercept & 0.12 & $0.02-0.64$ & 0.08 & 0.002 & $0.02-0.40$ \\
\hline \multicolumn{6}{|l|}{ IBBA round } \\
\hline Round 1 & Reference & Reference & Reference & Reference & Reference \\
\hline Round 2 & 0.76 & $0.67-0.85$ & 1.19 & 0.230 & $0.90-1.58$ \\
\hline \multicolumn{6}{|l|}{ Current age, $y$} \\
\hline$<25$ & Reference & Reference & Reference & Reference & Reference \\
\hline $25-34$ & 1.18 & $1.05-1.33$ & 1.19 & 0.005 & $1.05-1.33$ \\
\hline $35+$ & 0.93 & $0.81-1.07$ & 0.93 & 0.311 & $0.81-1.07$ \\
\hline \multicolumn{6}{|l|}{ Literacy } \\
\hline Illiterate & Reference & Reference & Reference & Reference & Reference \\
\hline Literate & 0.87 & $0.80-0.95$ & 0.88 & 0.004 & $0.80-0.96$ \\
\hline \multicolumn{6}{|l|}{ Source of income other than sex work } \\
\hline No & Reference & Reference & Reference & Reference & Reference \\
\hline Yes & 0.90 & $0.82-0.99$ & 0.88 & 0.010 & $0.80-0.97$ \\
\hline \multicolumn{6}{|l|}{ Current marital status } \\
\hline Currently married & Reference & Reference & Reference & Reference & Reference \\
\hline Marriage dissolved & 1.50 & $1.37-1.65$ & 1.48 & $<0.001$ & $1.35-1.63$ \\
\hline Never married & 1.16 & $1.02-1.33$ & 1.15 & 0.039 & $1.01-1.31$ \\
\hline \multicolumn{6}{|l|}{ Age at sex debut, y } \\
\hline$<15$ & Reference & Reference & Reference & Reference & Reference \\
\hline $15+$ & 0.91 & $0.83-0.99$ & 0.91 & 0.029 & $0.83-0.99$ \\
\hline \multicolumn{6}{|l|}{ Duration in sex work, $y$} \\
\hline$<2$ & Reference & Reference & Reference & Reference & Reference \\
\hline $2-4$ & 1.26 & $1.10-1.43$ & 1.27 & $<0.001$ & $1.11-1.44$ \\
\hline $5-9$ & 1.48 & $1.29-1.69$ & 1.49 & $<0.001$ & $1.30-1.70$ \\
\hline $10+$ & 1.62 & $1.40-1.88$ & 1.64 & $<0.001$ & $1.41-189$ \\
\hline \multicolumn{6}{|l|}{ Place of solicitation } \\
\hline Home & Reference & Reference & Reference & Reference & Reference \\
\hline Brothel/Lodge/Dhaba & 1.72 & $1.49-199$ & 1.73 & $<0.001$ & $1.50-2.00$ \\
\hline Public places & 1.36 & $1.20-1.54$ & 1.36 & $<0.001$ & $1.20-1.54$ \\
\hline Other & 1.03 & $0.81-1.31$ & 1.05 & 0.711 & $0.82-1.33$ \\
\hline \multicolumn{6}{|l|}{ Carrying condom } \\
\hline No & Reference & Reference & Reference & Reference & Reference \\
\hline Yes & 1.20 & $1.10-1.31$ & 1.16 & 0.001 & $1.07-1.27$ \\
\hline \multicolumn{6}{|l|}{$\mathrm{NG} / \mathrm{CT}^{*}$} \\
\hline Yes & 1.35 & $1.17-1.56$ & 1.36 & $<0.001$ & $1.17-1.57$ \\
\hline No & Reference & Reference & Reference & Reference & Reference \\
\hline \multicolumn{6}{|l|}{ Experienced violence } \\
\hline No & Reference & Reference & Reference & Reference & Reference \\
\hline Yes & 1.35 & $1.19-1.53$ & 1.35 & $<0.001$ & $1.19-1.53$ \\
\hline \multicolumn{6}{|l|}{ Has a nonpaying main partner } \\
\hline No 1 r & 1.41 & $1.29-1.54$ & 1.29 & $<0.001$ & $1.15-1.45$ \\
\hline Yes & Reference & Reference & Reference & Reference & Reference \\
\hline Syphilis serological test result & & & & & \\
\hline Negative & Reference & Reference & Reference & Reference & Reference \\
\hline Positive & 2.33 & $2.09-2.60$ & 2.32 & $<0.001$ & $2.08-2.59$ \\
\hline Consistent condom use with clients & & & & & \\
\hline No & Reference & Reference & Reference & Reference & Reference \\
\hline Yes & 1.19 & $1.07-1.32$ & 1.19 & 0.001 & $1.07-1.31$ \\
\hline Baseline (round 1) HIV prevalence ${ }^{\S}$ & 1.05 & $1.04-1.07$ & 1.05 & $<0.001$ & $1.04-1.07$ \\
\hline Distal variable & & & & & \\
\hline Mean age at marriage of girls & 0.92 & $0.85-0.998$ & 0.93 & 0.076 & $0.87-1.01$ \\
\hline Program variables from CMIS & & & & & \\
\hline FSW coverage in 2006 & & & 1.00 & 0.480 & $0.99-1.01$ \\
\hline Difference in coverage between & & & 1.00 & 0.201 & $0.99-1.01$ \\
\hline 2008 and 2006 & & & & & \\
\hline Interaction between round and & & & & & \\
\hline Having a nonpaying partner & & & 1.24 & 0.010 & $1.05-1.45$ \\
\hline Difference in coverage between & & & 0.995 & 0.006 & $0.991-0.998$ \\
\hline $\begin{array}{l}2008 \text { and } 2006 \\
\text { Baseline (round 1) HIV prevalence }\end{array}$ & & & 0.98 & 0001 & $0.97-0.99$ \\
\hline
\end{tabular}


TABLE 4. (Continued)

\begin{tabular}{|c|c|c|c|c|}
\hline \multirow{2}{*}{$\begin{array}{l}\text { Characteristics } \\
\text { Random Part of the Model }\end{array}$} & \multicolumn{2}{|c|}{$\begin{array}{c}\text { Without Program Variables } \\
\text { and Interaction Terms }\end{array}$} & \multicolumn{2}{|c|}{$\begin{array}{c}\text { With Program Variables and } \\
\text { Interaction Terms }\end{array}$} \\
\hline & $\begin{array}{c}\text { Estimated } \\
\text { Variance }\end{array}$ & $\begin{array}{l}95 \% \text { CI of } \\
\text { Variance }\end{array}$ & $\begin{array}{c}\text { Estimated } \\
\text { Variance }\end{array}$ & $\begin{array}{c}95 \% \text { CI of } \\
\text { Variance }\end{array}$ \\
\hline \multicolumn{5}{|l|}{ Estimated district-level variance of } \\
\hline Intercept & 0.004 & $0.000002-0.035$ & $\begin{array}{l}0.026 \\
0.001\end{array}$ & $\begin{array}{l}\text { Not significantly } \\
\text { different from } 0\end{array}$ \\
\hline
\end{tabular}

The random intercept variance decreased from 0.4094 (95\% CI, 0.226-0.741) in the null model to 0.004 (95\% CI, 0.000002-0.035) in the model with a random effect for the round, but no program variables or interaction terms.

*Multilevel logistic regression model excluding program variables and interaction terms; -2 log likelihood ratio test: $\chi^{2}=97.54, P<0.001$

${ }^{\dagger}$ Multilevel logistic regression model including program variables and interaction terms; -2 log likelihood ratio test: $\chi^{2}=67.26, P<0.001$.

*Infection by either Neisseria gonorrhoeae or Chlamydia trachomatis.

${ }^{\S} \mathrm{HIV}$ prevalence $\%$ among FSWs in round 1 of IBBA.

ORs for every percentage increase in coverage or one percentage increase in difference in coverage.

CMIS indicates computerized monitoring information system.

Third, given the potential of antiretroviral therapy (ART) to decrease HIV transmission, ${ }^{25}$ the increase in ART coverage between the study rounds could have been involved in the decrease in HIV prevalence we observed, whereas it could not been directly assessed because information on ART use by HIV-infected women was not collected in the IBBA surveys. This favorable impact of ART on HIV prevalence is, however, unlikely in our study. Indeed, out of an estimated 2.6 million HIV-infected people in India, only 6845 received ART in 2005 , whereas coverage increased to 140,654 people on treatment (approximately $5 \%$ of all infected people) in 2008 and to 223,223 (approximately 9\% of all infected people) in 2009. ${ }^{26}$ Antiretroviral therapy coverage thus remained relatively low until 2008 to 2009 , by which time IBBA surveys among FSWs were completed in all districts. In addition, as ART improves survival, its expansion could have first led to an increase in HIV prevalence, despite a reduction in new HIV cases, as was recently observed in a highly affected community in South Africa. ${ }^{27}$ Consequently, if the increase in ART coverage between the study rounds had any impact on HIV prevalence trends during this period, it would likely have been to artificially mask a downward trend.

Finally, the first survey was carried out after more than 1 year of intervention in most districts, and the level of intervention coverage had already reached relatively high levels at that time; this could have led to an underestimation of the decrease of HIV prevalence between the study rounds and of the association between increases in program indicators and declines in HIV prevalence.

In conclusion, this study strongly suggests that the Avahan intervention, where appropriately implemented, had a favorable impact on HIV prevalence among FSWs in the 4 southern states

TABLE 5. Changes Observed in HIV Prevalence Among FSWs Between the Study Rounds (2005-2006 and 2008-2009) at Different Levels of the Independent Variables Having a Significant Statistical Interaction With the Study Round*, 24 Districts of South India

\begin{tabular}{|c|c|c|c|c|}
\hline $\begin{array}{l}\text { Factors Having a Significant } \\
\text { Interaction With the Round }\end{array}$ & $\mathbf{A O R}^{\dagger}$ & $95 \% \mathrm{CI}^{+}$ & $\boldsymbol{P}$ & $\begin{array}{l}P \text { value of the } \\
\text { Interaction Term }\end{array}$ \\
\hline Having a main nonpaying partner & & & & 0.012 \\
\hline Yes & 0.84 & $0.72-0.97$ & 0.02 & \\
\hline No & 0.68 & $0.59-0.79$ & $<0.001$ & \\
\hline Baseline HIV prevalence $^{\S}$ & & & & 0.003 \\
\hline Minimum value $(3.2 \%)$ & 1.00 & $0.80-1.25$ & 0.996 & \\
\hline 1st quartile $(11.3 \%)$ & 0.86 & $0.74-0.998$ & 0.047 & \\
\hline 2nd quartile $(14.8 \%)$ & 0.81 & $0.71-0.92$ & $<0.001$ & \\
\hline 3rd quartile $(21.5 \%)$ & 0.72 & $0.63-0.81$ & $<0.001$ & \\
\hline Maximum value (37.3\%) & 0.54 & $0.42-0.69$ & $<0.001$ & \\
\hline $\begin{array}{l}\text { Difference in FSW coverage between } \\
2008 \text { and } 2006^{\S}\end{array}$ & & & & 0.008 \\
\hline Minimum value $(-8.9 \%)$ & 0.94 & $0.77-1.16$ & 0.564 & \\
\hline 1st quartile $(11.0 \%)$ & 0.85 & $0.73-0.98$ & 0.024 & \\
\hline 2nd quartile $(24.9 \%)$ & 0.78 & $0.70-0.89$ & $<0.001$ & \\
\hline 3 rd quartile $(56.6 \%)$ & 0.66 & $0.57-0.77$ & $<0.001$ & \\
\hline Maximum value $(106.3 \%$ \% & 0.51 & $0.37-0.69$ & $<0.001$ & \\
\hline
\end{tabular}

*The results presented in this table differ slightly from those in Table 4 because here, for the sake of simplicity, we used 3 different models with only 1 interaction variable in each of them (whereas in Table 4, we used 1 model including all the interaction terms); however, the AOR corresponding to each of the main variable and its interaction with round was similar in the 3 separate models and the model used for Table 4.

${ }^{\dagger} \mathrm{AOR}$ comparing HIV prevalence in round 2 with that in round 1 at different levels of each independent variable interacting with the round (adjusted for all the independent variables listed in Table 4).

$\$ 95 \%$ CI of the AOR.

${ }^{\S}$ At the district level.

"Coverage can be more than $100 \%$ because the denominator of this indicator is based on the estimate of the size of the FSW population at any moment in the district, whereas the number of women actually covered in the district could be higher than the denominator in places with high turnover of FSWs (mean duration of presence of the FSWs in the district of less than 1 year). 
of India covered by the intervention. The triangulation of our results with those from other approaches used in the Avahan evaluation $^{5-8,23}$ suggests a major overall impact of this program on the HIV epidemic in southern India. Interventions targeting most at-risk populations, such as FSWs, should be scaled up in all countries where specific vulnerable populations contribute significantly to the spread of HIV.

\section{REFERENCES}

1. Chandrasekaran P, Dallabetta G, Loo V, et al. Evaluation design for large-scale HIV prevention programmes: The case of Avahan, the India AIDS initiative. AIDS 2008; 22(suppl 5):S1-S15.

2. Laga M, Rugg D, Peersman G, et al. Evaluating HIV prevention effectiveness: The perfect as the enemy of the good. AIDS 2012; 26:779-783.

3. Boily MC, Lowndes CM, Vickerman P, et al. Evaluating large-scale HIV prevention interventions: Study design for an integrated mathematical modelling approach. Sex Transm Infect 2007; 83:582-589.

4. Lowndes CM, Alary M, Verma S, et al. Assessment of intervention outcome in the absence of baseline data: 'Reconstruction' of condom use time trends using retrospective analysis of survey data. Sex Transm Infect 2010; 86(suppl 1):i49-i55.

5. Boily MC, Pickles M, Lowndes CM, et al. Positive impact of a large-scale HIV prevention programme among female sex workers and clients in South India. AIDS 2013; 27:1449-1460.

6. Pickles M, Foss AM, Vickerman P, et al. Interim modelling analysis to validate reported increases in condom use and assess HIV infections averted among female sex workers and clients in southern India following a targeted HIV prevention programme. Sex Transm Infect 2010; 86(suppl 1):i33-i43.

7. Pickles M, Boily MC, Vickerman P, et al. Assessment of the population-level effectiveness of the Avahan HIV-prevention programme in South India: A preplanned, causal-pathway-based modelling analysis. Lancet Global Health 2013. http://dx.doi.org/10.1016/ S2214-109X(13)70083-4.

8. Ng M, Gakidou E, Levin-Rector A, et al. Assessment of populationlevel effect of Avahan, an HIV-prevention initiative in India. Lancet 2011; 378:1643-1652.

9. Boerma T, de Zoysa I. Beyond accountability: Learning from largescale evaluations. Lancet 2011; 378:1610-1612.

10. Alary M, Jayachandran AA, Lowndes CM, et al. Ecological analysis of the association between high-risk population parameters and HIV prevalence among pregnant women enrolled in sentinel surveillance in four Southern India states. Sex Transm Infect 2010; 86(suppl 1):i10-i16.

11. Vickerman P, Foss AM, Pickles M, et al. To what extent is the HIV epidemic in southern India driven by commercial sex? A modelling analysis. AIDS 2010; 24:2563-2572.

12. Verma R, Shekhar A, Khobragade S, et al. Scale-up and coverage of Avahan: A large-scale HIV-prevention programme among female sex workers and men who have sex with men in four Indian states. Sex Transm Infect 2010; 86(suppl 1):i76-i82.
13. Banandur P, Rajaram SP, Mahagaonkar SB, et al. Heterogeneity of the HIV epidemic in the general population of Karnataka state, south India. BMC Public Health 2011; 11(suppl 6):S13.

14. Ramesh BM, Moses S, Washington R, et al. Determinants of HIV prevalence among female sex workers in four south Indian states: Analysis of cross-sectional surveys in twenty-three districts. AIDS 2008; 22(suppl 5):S35-S44.

15. Saidel T, Adhikary R, Mainkar M, et al. Baseline integrated behavioural and biological assessment among most at-risk populations in six high-prevalence states of India: Design and implementation challenges. AIDS 2008; 22(suppl 5):S17-S34.

16. Munro HL, Pradeep BS, Jayachandran AA, et al. Prevalence and determinants of HIV and sexually transmitted infections in a general population-based sample in Mysore district, Karnataka state, southern India. AIDS 2008; 22(suppl 5):S117-S125.

17. Thamattoor UK, Thomas T, Banandur P, et al. Multi-level analysis of the predictors of HIV prevalence among pregnant women enrolled in sentinel surveillance in four southern India states. Sex Transm Infect 2011; 87(suppl 1):A182.

18. Mainkar MM, Pardeshi DB, Dale J, et al. Targeted interventions of the Avahan program and their association with intermediate outcomes among female sex workers in Maharashtra, India. BMC Public Health 2011; 11(suppl 6):S2.

19. Ramesh BM, Beattie TS, Shajy I, et al. Changes in risk behaviours and prevalence of sexually transmitted infections following HIV preventive interventions among female sex workers in five districts in Karnataka state, south India. Sex Transm Infect 2010; 86(suppl 1):i17-i24.

20. Reza-Paul S, Beattie T, Syed HU, et al. Declines in risk behaviour and sexually transmitted infection prevalence following a communityled HIV preventive intervention among female sex workers in Mysore, India. AIDS 2008; 22(suppl 5):S91-S100.

21. Deering KN, Boily MC, Lowndes CM, et al. A dose-response relationship between exposure to a large-scale HIV preventive intervention and consistent condom use with different sexual partners of female sex workers in southern India. BMC Public Health 2011; 11(suppl 6):S8.

22. Yadav D, Ramanathan S, Goswami P, et al. Role of community group exposure in reducing sexually transmitted infection-related risk among female sex workers in India. PLoS One 2013; 8:e78361.

23. Banandur P, Mahajan U, Potty RS, et al. Population-level impact of Avahan in Karnataka state, south India using multilevel statistical modelling techniques. J Acquir Immune Defic Syndr 2013; 62:239-245.

24. Habicht JP, Victora CG, Vaughan JP. Evaluation designs for adequacy, plausibility and probability of public health programme performance and impact. Int J Epidemiol 1999; 28:10-18.

25. Cohen MS, Chen YQ, McCauley M, et al. Prevention of HIV-1 infection with early antiretroviral therapy. N Engl J Med 2011; 365:493-505.

26. National AIDS Control Organisation and National Institute of Medical Statistics Ministry of Health and Family Welfare GoI. Annual Report 2011-122011, Available at: http://www.nacoonline.org/upload/ Publication/Annual\%20Report/NACO_AR_Eng\%202011-12.pdf.

27. Zaidi J, Grapsa E, Tanser F, et al. Dramatic increases in HIV prevalence after scale-up of antiretroviral treatment: A longitudinal populationbased HIV surveillance study in rural kwazulu-natal. AIDS 2013; 27:(Epub ahead of print) DOI:10.1097/QAD.0b013e328362e832. 